\title{
PHYTOCHEMICAL STATUS, ANTIBACTERIAL ACTIVITY AND ANTIOXIDANT PROPERTY OF DATURA METEL L.
}

\author{
JITHU U. KRISHNAN*, MEERA GEORGE, AJESH G. \\ Post Graduate and Research Department of Zoology, Mar Ivanios College, Nalanchira, Thiruvananthapuram, Kerala, India \\ Email: jithuukrishnan@gmail.com
}

Received: 02 Jan 2017, Revised and Accepted: 31 Apr 2017

\section{ABSTRACT}

Objective: Medicinal plants are a source of great economic value all over the world and are on the front dusk of traditional medicine. Daturametel L, is one among the foresaid and this plant can be explored further as per its diversity of uses and on the basis of wide range of chemical compounds reported to be present in various parts of the plant. In the present investigation, Phyto-chemistry of $D$. metel has been analysed along with its antibacterial property.

Methods: The selected plant leaves were collected and powdered. The bioactive compounds were extracted by using different solvents. Various phytochemical tests for alkaloids, flavonoids, saponins, steroids, terpenoids, tannins, glycosides and amino acids were done accordingly with standard protocol of testing. The study also extends to view the anti-bacterial potential by determining inhibition of growth using agar well diffusion method.

Results: Phytochemical analysis reflected the presence of compounds like alkaloids, flavonoids, saponins, tannins, glycosides, and amino acids. It was noted that steroids and tannins are absent. Antimicrobial activity proves extract of ethanolis the most promising against the pathogens from the rest screened.

Conclusion: Thearticle addresses, the undocumented knowledge regarding the phytochemical profile of $D$. metel which demand further exploration widely to serve Humanity. Antimicrobial potential of ethanol extract are very promising to deliver it as a pharmaceutical.

Keywords: Daturametel, Phytochemical extraction, Antimicrobial activity, Traditional medicine

(C) 2017 The Authors. Published by Innovare Academic Sciences Pvt Ltd. This is an open access article under the CC BY license (http://creativecommons.org/licenses/by/4.0/) DOI: http://dx.doi.org/10.22159/ijcpr.2017v9i3.19969

\section{INTRODUCTION}

Daturametel L., with vernacular name "Dhutura" in Bengali-Indian language, is a shrub with ever green branches. It is a perennial herbaceous plant, belonging to the Solanaceae family and often reaches a height of $1.5 \mathrm{~m}$. Leaves are simple, alternate, dark green, broadly ovate and shallowly lobed. Flowers are large, solitary, and trumpet-shaped with a sweet fragrance usually appreciated in the mornings and evenings, with a wide range of colours, ranging from white to yellow and light to dark purple. The flowers are bisexual and are pollinated by insects. The fruit is in the form of a capsule covered with short spines. Datura can tolerate average soil but prefers soil which is rich and moist or even very alkaline soil but hardly survives under shade. It prefers a warm temperature and is distributed in warmer regions of the world (Drake et al., 1996) [1]. Datura probably is of American origin and widely cultivated in all tropical and subtropical regions for its beautiful flower SD metel can also be found in East Asia or India, and is used in traditional Bangladeshi herbal medicine. In Traditional Chinese Medicine, the flowers of D. metel are known as baimantuoluo and used for skin inflammation and psoriasis (Wang et al., 2008) [2]. In Ayurvedic medicine, seeds of the plant are used to treat skin rashes, ulcers, bronchitis, jaundice and diabetes (Agharkar et al., 1991) [3]. In Brazil, seeds are used for tea making which would serve as a sedative and flowers are dried and smoked as cigarettes (Agra et al., 2007) [4]. There are various species of Datura which are now cultivated for the production of secondary metabolites. Many different Alkaloids are found in the whole plant of Datura, which increased gradually with increase in age of the plant (Afsharypuor et al., 1995) [5]. Main constituents of the Datura plant are a huge number of tropane alkaloids (hyoscyamine, hyoscine, littorine, acetoxytropine, valtropine, fastusine, fastusinine), a number of with anolides and various trigloyl esters of tropine and pseudotropine (Afsharypuor et al., 1995) [5]. Calystegines, the nortropane alkaloids with glycosidase inhibitory activity, have also been found in various
Datura species (Ghani, 2003) [6]. The root contains higher amount of atropine compared to the other parts which is a common drug used to dilate pupil for eye examination. The aerial parts usually accumulated relatively higher amounts of scopolamine and relatively lower amounts of atropine as compared to the root of the plant (Afsharypuor et al., 1995) [5]. Thus the plant is a potential source of secondary metabolites which are possible sharp tools for medical cure.

\section{MATERIALS AND METHODS}

\section{Collection of leaves}

The leaves were collected from the field of Nalanchira, Thiruvananthapuram, Kerala $\left(8.52^{\circ} \mathrm{N}, 76.94^{\circ}\right.$ E). The collected leaves were washed with water to remove dust and then washed leaves were shade dried for $14 \mathrm{~d}$. After drying the leaves were ground into powder form using a mixer.

\section{Extract preparation}

Extraction procedure was done according to the method of Vikrant Arya et al. (2011) [7]. Extracts were prepared by using four solvents petroleum ether, ethyl acetate, acetone, methanol and ethanol.

\section{Preliminary phytochemical screening}

The phytochemical tests were done for analysing different chemical groups present in the extracts. These were done to find out the presence of bioactive chemical constituents such as alkaloids, flavonoids, saponins, steroids, terpenoids, tannins, glycosides, and amino acid compounds by the following procedure.

\section{Test for alkaloids}

$3 \mathrm{ml}$ of extract was added to $1 \% \mathrm{HCl}$ and then allowed to steam bath. Few drops of Mayer and Wagner's reagent (make: Sigma Aldrich) was added to the mixture. Turbidity indicates the presence of alkaloids. 


\section{Test for flavonoids}

To $1 \mathrm{ml}$ of extract, $1 \mathrm{ml}$ of $10 \%$ lead acetate was added. Formation of yellow precipitate showed the presence of flavonoids.

\section{Test for saponins}

$2 \mathrm{ml}$ of extract was shaken vigorously with $5 \mathrm{ml}$ of distilled water and warmed. The formation of stable foam indicates the presence of saponins.

\section{Test for steroids}

$2 \mathrm{ml}$ of extract was dissolved in chloroform; $2 \mathrm{ml}$ of concentrated sulphuric acid was added to the mixture. Red colour formation indicates the presence of steroids.

\section{Test for terpenoids}

To $1 \mathrm{ml}$ of extract, $0.5 \mathrm{ml}$ of acetic anhydride was added. And then few drops of concentrated sulphuric acid were added to the mixture. Bluish green precipitate showed the presence of terpenoids.

\section{Test for tannins}

To $2 \mathrm{ml}$ of extract, $2 \mathrm{ml}$ of distilled water was taken and stirred. Few drops of ferric chloride solution were added. The formation of green precipitate showed the presence of tannins.

\section{Test for glycosides}

$2 \mathrm{ml}$ of extract was dissolved in chloroform and $2 \mathrm{ml}$ of acetic acid was added to the mixture. The solutions were cooled and then add few drops of sulphuric acid. A colour change from blue to green indicates the presence of glycosides.

\section{Test for amino acids}

$1 \mathrm{ml}$ of extract was treated with few drops of Ninhydrin reagent (make: Sigma Aldrich). A purple colour indicates the presence of amino acids.

\section{Antioxidant activity}

Oxygen scavenging activity was estimated using three methods via. the total phenolic content, reducing power assay and the DPPH radical scavenging.

\section{Total phenolic content}

Total phenolic content of Daturametel solvent extracts was determined (Meda et al., 2005) [8]. Gallic acid was used as standard. Four concentrations $25,50,75,100 \mathrm{mg} / \mathrm{ml}$ of solvent extracts were taken in 4 test tubes. $2.5 \mathrm{ml}$ of 10 -fold diluted Folin-Ciocalteu reagent (make: Sigma Aldrich) was added and $2.0 \mathrm{ml}$ of $7.5 \%$ sodium carbonate was added. The reaction mixture was incubated at $40{ }^{\circ} \mathrm{C}$ for $30 \mathrm{~min}$. Finally, absorbance was read at $760 \mathrm{~nm}$. Three replications were done for this.

\section{Reducing power}

The ability of extracts to reduce iron (III) was determined by the method of Yildirim et al.2000 [9]; four concentrations 25, 50, 75,100 $\mathrm{mg} / \mathrm{ml}$ of Daturametel solvent extracts were mixed with $2.5 \mathrm{ml}$ of phosphate buffer and $2.5 \mathrm{ml}$ of potassium ferricyanide. Then, the mixture was incubated at $50^{\circ} \mathrm{C}$ for $30 \mathrm{~min}$. $2.5 \mathrm{ml}$ of Trichloroacetic acid was added and the mixture was centrifuged at $3000 \mathrm{rpm}$ for 10 min. $2.5 \mathrm{ml}$ of supernatant solution was taken and mixed with $2.5 \mathrm{ml}$ of distilled water and $0.5 \mathrm{ml}$ of ferric chloride. Lascorbic acid was used as standard. Finally, the absorbance of all samples was measured at $700 \mathrm{~nm}$. This was done in three replicates

\section{DPPH radical scavenging}

The DPPH assay was done according to the method of Rivero-perez et al. (2008) [10]. The DPPH scavenging effects of the different extracts petroleum ether, ethyl acetate, acetone, methanol and ethanol were determined. Ascorbic acid was used as a standard. The blank contained $1 \mathrm{ml}$ of distilled water. $1 \mathrm{ml}$ of extract was taken at four concentrations of $25,50,75,100 \mathrm{mg} / \mathrm{ml}$ in 4 test tubes. $1 \mathrm{ml}$ of $0.2 \mathrm{mmol}$ DPPH ethanol solution was added. The mixture was vortexed vigorously for 1 minute and kept in dark for $60 \mathrm{~min}$. The absorbance of all samples was measured at $517 \mathrm{~nm}$. This was done in triplicate. The percentage inhibition was calculated using the formula,

DPPH inhibition $(\%)=\%$ inhibition $=[($ Absorbance of controlAbsorbance of test sample)/Absorbance of control] x100

\section{Antibacterial activity test organisms}

Four pathogenic bacteria viz., Bacillus subtilis, Bacillus cereus, Salmonella typhi, and E. coli were collected from Pathogen laboratory, Medical College, Thiruvananthapuram. The cultures were sub cultured and maintained on nutrient agar slants in refrigerator at $4^{\circ} \mathrm{C}$.

Inoculum preparation: Stock Cultures were maintained at $4{ }^{\circ} \mathrm{C}$ on slants of nutrient agar. Active cultures for experiments were prepared by transferring a loopful of culture from the stock to test tubes of nutrient broth for bacteria and incubating for $24 \mathrm{~h}$ at $37{ }^{\circ} \mathrm{C}$ and $25^{\circ} \mathrm{C}$ respectively. The cultures were diluted with fresh nutrient broth. Agar well diffusion method: The antibacterial screening of the crude extracts were evaluated by agar well diffusion method. After solidification of the medium, a well was made in the plates with sterile borer $(5 \mathrm{~mm})$. The extract compound $100 \mu \mathrm{l}$ was introduced into the well and the plates were incubated at $37^{\circ} \mathrm{C}$ for $24 \mathrm{~h}$. All samples were tested in triplicates. The microbial growth was determined by measuring the diameter of the zone of inhibition.

Table 1: Phytochemical analysis of Daturametel

\begin{tabular}{llllll}
\hline S. No. & Phytochemical compounds & Petroleum ether & Ethyl acetate & Acetone & Methanol \\
\hline 1 & Alkaloid & + & + & + & + \\
2 & Flavonoid & - & + & + & + \\
3 & Saponine & + & + & + & + \\
4 & Steroid & - & - & - & - \\
5 & Terpenoid & - & - & - & - \\
6 & Tannin & + & - & + & + \\
7 & Glucosides & - & + & - & + \\
8 & Amino acids & + & + & + & + \\
\end{tabular}

Table 2: Agar well diffusion method

\begin{tabular}{|c|c|c|c|c|}
\hline \multirow[t]{2}{*}{ Extract in } & \multicolumn{4}{|c|}{ Growth inhibition over different microbes (mm) } \\
\hline & Bacillus subtilis & Bacillus cereus & Salmonellatyphi & E. coli \\
\hline Petroleum ether & 0 & 0 & 0 & 0 \\
\hline Ethyl acetate & 3 & 2 & 0 & 0 \\
\hline Acetone & 20 & 14 & 17 & 18 \\
\hline Methanol & 21 & 17 & 16 & 17 \\
\hline Ethanol & 26 & 24 & 24 & 21 \\
\hline
\end{tabular}




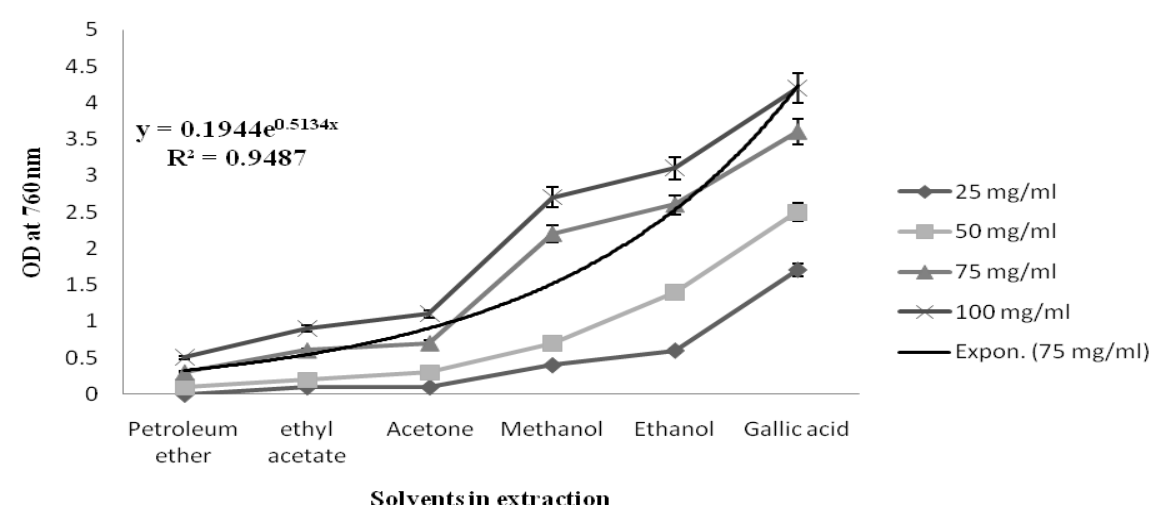

Fig. 1: Total phenolic concentration of different solvent extracts of Daturametel leaves

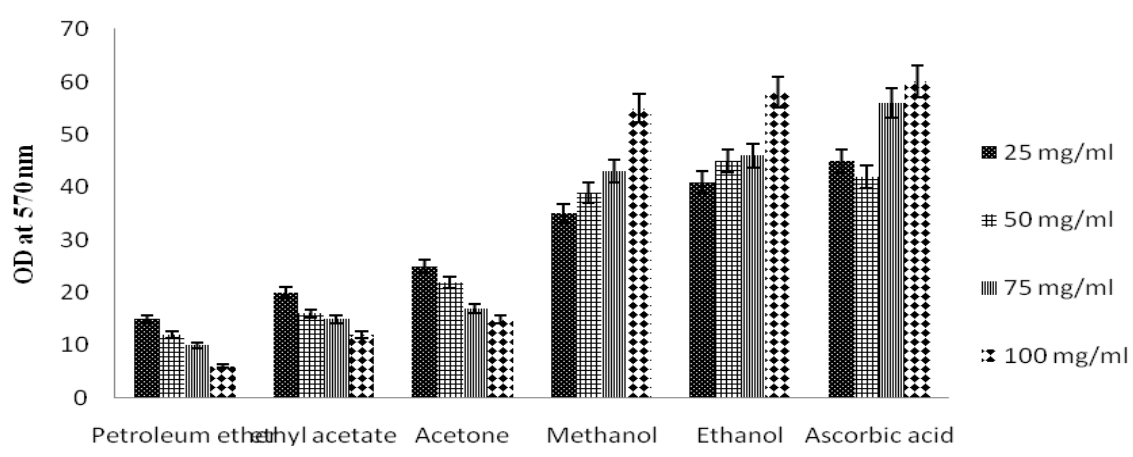

Fig. 2: DPPH radical scavenging activities of different solvent extracts of Daturametel leaves

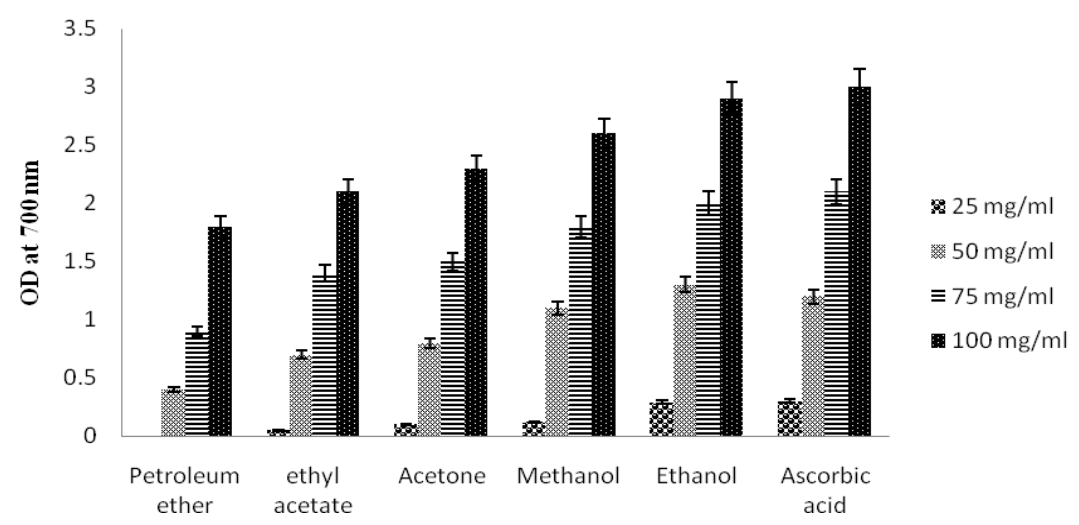

Fig. 3: Reducing power of different solvent extracts of Daturametel leaves
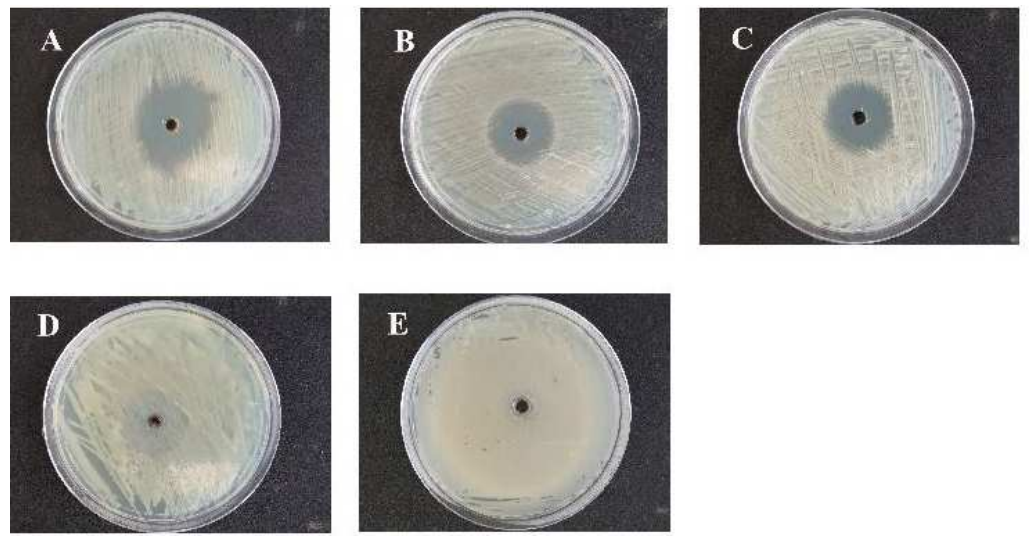

Fig. 4: Anti-microbial property exhibited by Daturametel leaf extracts in various solvents on Bacillus subtilis. A: Ethanol; B: Methanol; C: Acetone; D: Ethyl acetate; E: Petroleum ether 


\section{RESULTS AND DISCUSSION}

\section{Phytochemical screening}

Phytochemical screening result shows the alkaloids, flavonoids, saponins, tannins, glycosides and non-protein amino acids were present in leaf crude extracts of Daturam et el, whereas steroids and terpenoids were absent in all the extracts (table 1). However, ethanol crude extracts showed positive test for alkaloids, flavonoids, saponins, tannins, glycosides, amino acids, but steroids and terpenoids are absent. Methanol crude extracts shows the presence of alkaloids, flavonoids, saponins, tannins and amino acids but glycosides, steroids and terpenoids were absent. In ethyl acetate crude extracts the chemical compounds such as alkaloids, flavonoids, saponins, glycosides and amino acids were present but tannins, steroids and terpenoids were absent. Petroleum ether crude extracts shows the presence for alkaloids, saponins, tannins and amino acids, whereas absent in all other screening test. Phytochemical constituents which are present in plant samples are known to be biologically active compounds and they are responsible for different activities such as antimicrobial, antioxidant, antifungal, anticancer and antidiabetic (Hossain and Nagooru; 2011) [11]. Different phytochemicals have been found to possess a wide variety of pharmacological activities, which may help in protection against chronic diseases. Tannins, glycosides, saponins, flavonoids, and amino acids have hypoglycemic and anti-inflammatory activities. Terpenoids, and steroids shows analgesic properties and central nervous system (CNS) activities. Saponins are involved in plant defence system because of their antimicrobial activity (Ayoola et al., 2011) [12] and also possess hypocholesterolemic and antidiabetic properties. The most effective bio active compounds are alkaloids, saponins and aminoacids-these were found in all four types of crude extracts. Flavonoids were found in ethanol, methanol and ethylacetate except petroleum ether extracts. Ethanol and methanol extracts shows the presence of majority phytoconstituents. Many reports are available on flavanoid groups which exhibiting high potential biological activities such as antioxidant, anti-inflammatory, antiallergic reactions (Anyasor et al., 2010 [13]; Chao et al., 2002 [14]; Igbinosa et al., 2009 [15]; Thitilertdecha, 2008 [16]).

\section{Antioxidant activity}

From the assay it's proved that D. metel is a pool of antioxidants.

\section{Total phenolic content}

The amount of total phenolic compounds of crude extract was determined by using linear gallic $\operatorname{acid}\left(\mathrm{y}=8.7231 \mathrm{X}+0.087 ; \mathrm{R}^{2}=0.9971\right)$. The total phenolic content ranges from $0.5-4.2 \mathrm{mg} / \mathrm{ml}$ (fig. 1). Among different types of extracts ethanol shows highest antioxidant activity whereas petroleum ether shows lowest antioxidant activity. In many plants, phenolic compounds show secondary metabolites with antioxidant and antibacterial activities. In many countries, $80 \%$ of people make use of medicinal plants for maintaining good health because of antioxidant property. Most medicinal plants contain higher phenolic compounds such as monophenols and polyphenols. Usually in many plants leaf shows the higher phenolic content (Pyo et al., 2004 [17]; Wong and Kitts, 2006 [18]). Many studies have proved that the phenolic content in the plants are associated with their antioxidant activities, probably due to their redox properties, which allow than to act as reducing agents and hydrogen donors(Chang et al., 2001) [19].

\section{DPPH radical scavenging}

The photometric evaluation of the antioxidant activity of ethanol extract of Daturametel leaves shows good antioxidant capacity. The inhibition percentage of different extracts ranges from 6 to 53 $\mathrm{mg} / \mathrm{ml}$ (fig. 2). In all extracts, ethanol showed maximum inhibition whereas petroleum ether showed minimum inhibition. Ethanol extract contain highest amount of total phenolics, was found to be most effective radical scavenger followed by methanol, ethyl acetate and petroleum ether extract. DPPH is used to evaluate the free radicals (Porto et al., 2000) [20]. Free radicals are involved in the process of lipid per oxidation which is considered as a major role in chronic diseases (Dorman et al., 2003) [21]. All extracts from Daturametel leaves exhibited a significantly greater hydroxyl radical scavenging activity than the ascorbic acid.

\section{Reducing power}

Many studies have indicated that the electron donation capacity of compounds is related with antioxidant activity. The reduction ability was estimated through $\mathrm{Fe}^{3+}-\mathrm{Fe}^{2+}$. Ethanol extract exhibits maximum reducing activity and Petroleum ether extract exhibits minimum activity. All extracts showed electron donation capacity. The higher absorbance value indicated that higher antioxidant activity. Ethanol extract contain highest amount of total phenolics and it is the most potent reducing agent (fig. 3). Relation between iron (III) reducing activity and total phenol content have been reported in the literature (Benzie et al., 1999) [22]; however the correlation may not be always linear (Yildirim et al., 2000) [9].

\section{Anti-microbial activity}

The results of present study showed that the selected plant Daturametel extracts were effective against the bacterial species tested. This can be used to treat Bacillus subtilis, Bacillus cereus, Salmonella typhiand E. coli. fig. 4; lists the inhibitory effect of different solvent extracts of $D$. metel on the test bacteria. It is observed that the leaf content has more phytochemicals as compared to other plant parts where as it is very less in stem (Jamdhade et al., 2010) [23]. Current study agrees that the leaf extracts of $D$. metel inhibited the tested bacterial isolates. The higher inhibition on the bacterial species by ethanol extract of the leaves $(26 \mathrm{~mm})$, methanol leaf extract $(21 \mathrm{~mm})$ and acetone leaf extract $(20$ $\mathrm{mm}$ ) (table 2). According to Prasanna and Raghunathan (2014) [24], in most cases the methanol and ethanol extracts exhibited higher antibacterial effects than the corresponding extracts.

\section{CONCLUSION}

High antioxidant activity was observed in ethanol extracts of Daturametel when compared to other extracts. The extracts of $D$. metel show the presence of secondary metabolites such as alkaloids, flavonoids, saponins, tannins, glycosides and non-protein amino acids. Ethanol contains highest amount of phenolic content and also exhibit strongest antioxidant capacity in the entire assay used. According to the phenolics result ethanol crude extract could be used as natural antibiotics for different diseases. The bioactive compounds from $D$. metel serve as good phytotherapeutic agent. The present antimicrobial of different crude extracts of Daturametel showed that the methanol, ethanol, and acetone from dry leaves shows highest zone of inhibition against the employed bacteria. This plant crude extracts in ethanol could serve as potential sources of antimicrobial agents and hold potential for being an antimicrobial drug.

\section{CONFLICT OF INTERESTS}

\section{Declare none}

\section{REFERENCES}

1. Drake RE, Mueser KT, Clark RE, Wallach MA. The course, treatment, and outcome of substance disorder in persons with severe mental illness. Am J Orthopsychiatry 1996;66:42-51.

2. Wang XL. Accounting for autocorrelation in detecting mean shifts in climate data series using the penalized maximal t or $\mathrm{F}$ test. J Appl Meteor Climatol 2008;47:2423-44.

3. Agharkar SP. Medicinal plants of bombay presidency. Scientific Publ. Jodhpur. India; 1991. p. 1-2.

4. Agra MF, Baracho GS, Nurit K, Basílio IJLD, Coelho VPM. Medicinal and poisonous diversity of the flora of "CaririParaibano", Brazil. J Ethnopharmacol 2007;111:383-95.

5. Afsharypuor S, Mostajeran A, Mokhtary R. Variation of scopolamine an atropine in different parts of Daturametel during development. Planta Med 1995;61:383-4.

6. Ghani A. Medicinal plants of Bangladesh with chemical constituents and uses. 2nd edition. Asiatic Society of Bangladesh 2003.23(1 Suppl 2):82-94.

7. Arya Vikrant, CP Kashyap, Bandana Tikka, Shikha Sharma, Sweta Kumari, Priti Verma, et al. Human cancer cell lines-a brief communication. J Chem Pharm Res 2011;3:514-20.

8. Meda A, Lamien CE, Romito M, Millogo J, Nacoulma OG. Determination of the total phenolic, flavonoid and proline 
contents in Burkina Fasan honey, as well as their radical scavenging activity. Food Chem 2005;91:571-7.

9. Yildirim A, Mavi A, Oktay AA, Algur OF, Bilaloglu V. Comparison of antioxidant and antimicrobial activity of tilia (TiliaargentaDesf. Ex. D. C.), sage (Salvia triloba L.) and black tea (Camellia sinensis L.) extracts. J Agric Food Chem 2000;48:5030-4.

10. Rivero Pérez MD. Contribution of anthocyanin fraction to the antioxidant properties of wine. Food Chem Toxicol 2008.; 46:2815-22.

11. Hossain MA, Nagooru MR. Biochemical profiling and total flavonoids contents of leaves crude extract of endemic medicinal plant corydyline terminal is L. Kunth. Pharm J 2011;3:25-9.

12. Ayoola GA, Coker HAB, Adesegun SA, Adepoju Bello AA, Obaweya K, Ezennia EC, et al. Phytochemical screening and oxidant activities of some selected medicinal plants used for malaria therapy in south western Nigeria. Trop J Pharm Res 2008; 7:1019-24.

13. Anyasor GN, Ogunwenmo KO, Oyelana OA, Akpofunure BE. Phytochemical constituents and antioxidant activities of aqueous and methanol stem extracts of scostusaferkerGawl (costaceae). Afr J Biotechnol 2010;9:4880-4.

14. Chao PDL, Hsiu SL, Hou YC. Flavonoids inherbs; biological fates and potential interactions with xenobiotics. J Food Drug Anal 2002;10:219-28.

15. Igbinosa 00, Igbinosa EO, Aiyegoro OA. Antimicrobial activity and phytochemical screening of stem bark extracts from Jatropha Curcas (Linn). Afr J Pharm Pharamacol 2009;3:58-62.

16. Thitilertdecha $\mathrm{N}$, Teerawutgulrag A, Rakariyatham $\mathrm{N}$. Antioxidants and antibacterial activities of Nepheliumappaceum L. extracts. Food Sci Technol 2008;1:2029-35.
17. Pyo YH, Lee TC, Logendra L, Rosen RT. Antioxidant activity and phenolic compounds of swiss chard (Beta vulgaris subspecies cycla) extracts. Food Chem 2004;85:19-26.

18. Wong PYY, Kitts DD. Studies on the dual antioxidant and antibacterial properties of parsle (petroselinumcrispum) and Cilantro (Coriandrumsativum) extracts. Food Chem 2006; 97:505-15.

19. Chang ST, Wu JH, Wang SY, Kang PL, Yang NS, et al. Antioxidant activity of extracts from Acacia confusa bark and heartwood. J Agric Food Chem 2001;49:3420-4.

20. Porto CD, Calligaris S, Cellotti E, Nicoli MC. Antiradical properties of commercial cognacs assessed by the DPPH test. J Agric Food Chem 2000;48:4241-5.

21. Dorman HJD, Kosar M, Kahlos K, Holm Y, Hiltunen R. Antioxidant properties and composition of aqueous extracts from Mentha species, hybrids, varieties, and cultivars. J Agric Food Chem 2003;51:4563-9.

22. Benzie IFF, Szeto YT. Total antioxidant capacity of teas by the ferric reducing antioxidant power assay. J Agric Food Chem 1999;47:633-6.

23. Jamdhade MS, SA Survase, MA Kare, AS Bhuktar. Antibacterial activity of genus Datura L. in Marathwada, Maharashtra. J Phytol 2010;2:42-5.

24. Prasanna K, Raghunathan D. Preliminary phytochemical screening and effect of Agelemarmelos extracts against bacterial cold-water disease causing organism. World J Pharm Res 2014;3:498-507.

\section{How to cite this article}

- Jithu U Krishnan, Meera George, Ajesh G. Phytochemical status, antibacterial activity and antioxidant property of Datura metel L.. Int J Curr Pharm Res 2017;9(3):106-110. 